\title{
A support programme for patients with dementia and their caregivers lowered institutionalisation rates initially
}

Eloniemi-Sulkava U, Notkola IL, Hentinen M, et al. Effects of supporting community-living demented patients and their caregivers: a randomized trial.J Am Geriatr Soc 2001 Oct;49:1282-7.

\section{QUESTION: In patients with dementia, does a 2 year support programme based on nurse case management prolong care in the community?}

Design

Randomised \{allocation concealed $\} *$, unblinded $\}^{*}$, controlled trial with 2 years of follow up.

\section{Setting}

5 municipalities in Finland.

\section{Patients}

100 patients who were $\geqslant 65$ years of age (mean age 79 y, $53 \%$ women), entitled to payments from the Social Insurance Institution for community care because they had dementia, and lived at home with primary support from an informal caregiver (mean age $64 \mathrm{y}, 69 \%$ women). Exclusion criteria were other severe diseases that might lead to institutionalisation or inability of patients and caregivers to participate in annual training courses. Follow up was $100 \%$.

\section{Intervention}

Patients were allocated to a support programme $(\mathrm{n}=53)$ or usual care $(n=47)$. The 2 year support programme consisted of systematic and comprehensive support for patients and their caregivers by a dementia family care nurse coordinator who had access to the physician. Support included advocacy for patients and caregivers, continuous and systematic counselling, annual training courses for patients and their caregivers, follow up calls, home visits, assistance with arrangements for social and healthcare services, and 24 hour availability by mobile telephone.

\section{Main outcome measures}

Time to institutionalisation and death at home.

Sources of funding:

Social Insurance

Institution, Finland, and

the Alzheimer

Foundation of Finland.

For correspondence:

U Eloniemi-Sulkava,

University of Kuopio,

Kuopio, Finland.

Ulla.Elomiemi@uku.fi

A modified version of this abstract appears in ACP Journal Club.

\section{Main results}

During the first months, the rate of institutionalisation was lower in the support programme group than in the usual care group (hazard ratio [HR] 0.12, 95\% CI 0.02 to 0.93; $\mathrm{p}=0.042$ ) but the benefit decreased over time (HR 1.18 , CI 1.02 to $1.36 ; \mathrm{p}=0.028$ ). By 2 years, the groups did not differ for institutionalisation rates $(\mathrm{p}>0.2)$ (table). By the end of the first year, 6 patients $(11 \%)$ in the support programme group and $3(6 \%)$ in the control group died in community care $(\mathrm{p}=0.49)$; by the end of the second year, 9 patients $(17 \%)$ in the support programme group and $8(17 \%)$ in the control group died.

Support programme $v$ usual care for patients with dementia and their caregivers at 2 yearst

\begin{tabular}{lllll} 
Outcome & $\begin{array}{l}\text { Support } \\
\text { programme }\end{array}$ & Usual care & RRI $(95 \% \mathrm{Cl})$ & NNH \\
\hline Institutionalisation & $32 \%$ & $30 \%$ & $7.7 \%(-40$ to 94$)$ & Not significant \\
\hline
\end{tabular}

†Abbreviations defined in glossary; RRI, $\mathrm{NNH}$, and $\mathrm{Cl}$ calculated from data in article.

\section{Conclusions}

In patients with dementia, the rate of institutionalisation was lower for those who received a support programme than those who received usual care during the first months, but the difference decreased with time. At 2 years, the groups did not differ for rates of institutionalisation.

*Information provided by author.

\section{COMMENTARY}

With the ageing of the population and restructuring of healthcare systems, greater expectations are and will be placed on informal caregivers to care for those with dementia. The study by Eloniemi-Sulkava et al makes an important contribution to our understanding of strategies that are effective in supporting informal caregivers of people with dementia. Although the results of most studies in this area have been inconclusive, ${ }^{1}$ a few have shown that training and counselling of family caregivers of individuals with dementia delayed admission to nursing homes. ${ }^{2}{ }^{3}$

The randomised controlled design is a strength of the study by Eloniemi-Sulkava et al; however, one must be cautious about generalising the results to countries other than Finland. It is interesting to note that in Finland, all individuals with dementia who require care are eligible for government payments independent of income. Limitations of the study include a sample size that may have been too small to detect a difference between the intervention and control groups and the absence of a cost analysis. Was the cost of the nurse with expertise in dementia care offset by the lower rates of institutionalisation during the first months? Further research (with larger sample sizes) is required to address these concerns.

Eloniemi-Sulkava et al recommend that the services of a dementia family care nurse coordinator be targeted to those with severe dementia. Home care programmes would benefit by having case managers with expertise in dementia care that would offer systematic and comprehensive support to individuals with dementia and their caregivers. As the authors point out, these case managers need continuous training and support and should have access to various healthcare professionals with expertise in dementia care.

Dorothy Forbes, $\mathrm{RN}, \mathrm{PhD}$ Associate Professor, College of Nursing University of Saskatchewan Saskatoon, Saskatchewan, Canada

1 Thompson C, Spilsbury K. Support for carers of people with Alzheimer's type dementia. Cochrane Database Syst Rev 2001;(2):CD000454.

2 Mittelman MS, Ferris SH, Shulman E, et al. A family intervention to delay nursing home placement of patients with Alzheimer disease. A randomized controlled trial. JAMA 1996;276:1725-31.

3 Brodaty H, Gresham M, Luscombe G. The Prince Henry Hospital dementia caregivers' training programme. Int J Geriatr Psychiatry 1997;12:183-92. 